\title{
The Effectiveness of the Combination of Cinnamon and Ginger with Exercise Training in the Treatment of Dysmenorrhea and Premenstrual
}

\author{
Syndrome
}

\author{
Behnoush Ebrahimi Azmoudeh ${ }^{1}$, Masoumeh Habibian² $^{2}$ Babisan Askari ${ }^{3}$
}

\begin{abstract}
Background \& Aims: Premenstrual syndrome (PMS) is a common disorder among young and middle-aged women, which is associated with various physical, cognitive, psychological, and emotional symptoms during the menstrual cycle in women. Approximately 70-80\% of women experience some degrees of PMS symptoms, and $20-40 \%$ of these women, the symptoms lead to disorders in their functioning and daily life. Today, considering the high prevalence of PMS and primary dysmenorrhea in women and the unknown causes of these disorders, various treatments have been proposed for the control or reduction of the pain intensity and symptoms of the disease. Herbal and sports non-pharmacological therapies have received more attention from researchers and women owing to their variety, fewer side-effects, and cost-effectiveness. Cinnamon and ginger are among the medicinal plants that are effective in the reduction of pain intensity. Cinnamon consumption is associated with no particular risks in humans, and previous findings have confirmed the effectiveness of cinnamon consumption in the reduction of pain intensity and the systemic symptoms of primary dysmenorrhea. Ginger is also known as an effective medicine in several traditional herbal remedies, such as the treatment of nausea, increasing appetite, treatment of indigestion, fever, and infections, and body cleansing, especially in East Asian countries. Researchers have reported that regular exercise is effective in reducing the symptoms of PMS, as well as the duration and intensity of primary dysmenorrhea pain. The present study aimed to assess the effectiveness of the combination of cinnamon and ginger with walking and stretching exercises on dysmenorrhea and PMS.

Materials \& Methods: This quasi-experimental study was conducted with a pretest-posttest design and a control group on the young women living in Ghaemshahr, Iran in 2019. Among the volunteers participating in the study, the individuals with regular menstrual periods, PMS (minimum of five signs of PMS), and primary dysmenorrhea (moderate-to-severe pain) were sampled via convenience sampling. After obtaining written consent, the selected candidates were enrolled in the study and divided into four groups of exercise, cinnamonginger, combination of exercise and cinnamon-ginger, and control by drawing lots. The exercise training program comprised of stretching exercises and walking three sessions per week for eight weeks. A cinnamonginger capsule $(500 \mathrm{mg}$ ) was administered thrice daily with the onset of pain within the first 72 hours of menstruation for two months. The patients were assessed before and eight weeks after the intervention using the visual analogue scale (VAS) of menstrual pain intensity, PMS screening tool, and PMS daily status. The VAS is a standard tool for the evaluation of pain intensity within the score range of 0-10, with score zero indicating no pain, scores 1-3 showing mild pain, scores 4-7 indicating moderate pain, and scores 8-10 showing severe pain. The subjects with the pain intensity score of higher than four were enrolled in the study. Cox menstrual symptom scale was used to measure the duration of pain (from the onset of pain to the end). Based on this criterion, the subjects were assigned five scores within the range of $0-4$, including the absence of pain, less than/equal to half an hour of pain, half to equal to one hour of pain, more than one hour of pain, and more than one day of pain, respectively. Data analysis was performed using paired t-test, the Mann-Whitney U test, oneway analysis of variance (ANOVA), Kruskal-Wallis test, and Tukey's test.

Results: The results of one-way ANOVA indicated no significant differences in the duration and period of menstruation, pain intensity, duration of pain, psychological symptoms (mood and behavioral symptoms), and
\end{abstract}

\footnotetext{
1. MS in Sports Physiology, Department of Physical Education and Sports Sciences, Islamic Azad University, Qaemshahar Branch, Qaemshahar, Iran

2. Associate Professor of Sports Physiology, Department of Physical Education and Sports Sciences, Islamic Azad University, Qaemshahar Branch, Qaemshahar, Iran $\quad$ (Corresponding author) Tel: +011-42241041 Email: habibian_m@yahoo.com

3. Assistant Professor of Sports Physiology, Department of Physical Education and Sports Sciences, Islamic Azad University, Qaemshahar Branch, Qaemshahar, Iran
} 
physical PMS symptoms at baseline. After eight weeks, the intensity and duration of primary dysmenorrhea pain and the scores of the physical and psychological PMS symptoms (mood and behavioral symptoms) significantly decreased in the intervention groups compared to the control group $(\mathrm{P}<0.05)$. Furthermore, the effects of the combination therapy on the rate of the changes in the intensity and duration of primary dysmenorrhea pain and scores of the physical and mental symptoms of PMS were more significant compared to the cinnamon-ginger and exercise groups. Meanwhile, the rate of the mean changes in the mood and physical symptoms of the cinnamon-ginger group was significantly higher compared to the exercise group.

Conclusion: According to the results, the duration and intensity of dysmenorrhea pain and physical and mental symptoms of PMS (mood and behavioral symptoms) decreased after eight weeks of the consuming the combination of cinnamon and ginger, and these changes were reinforced with the physical exercises. It seems that regular exercise as a source of psychological changes could reduce the duration and intensity of dysmenorrhea pain through decreasing the disorders associated with neurotransmitters (especially serotonin and gamma-aminobutyric acid), stress reduction, development of blood circulation, increasing the endorphins and neurotransmitters, and decreasing the serum aldosterone, body fat mass, and estrogen levels, thereby improving the symptoms of PMS. In addition, the anti-inflammatory effects of ginger were exerted through the inhibition of cyclooxygenase and lipoxygenase, followed by the reduction of leukotriene and prostaglandin. The examination of cinnamon compounds and their effects also indicated that cinnamaldehyde, eugenol, and terpene in cinnamon have analgesic, tranquilizing, and anti-inflammatory properties. As a result, the nonpharmacological interventions of walking and stretching exercises, simultaneous consumption of cinnamon and ginger, and combination therapy could be considered as effective treatments in improving the physical and psychological symptoms of PMS and decreasing the intensity and duration of primary dysmenorrhea pain in young women.

\section{Keywords: Cinnamon, Dysmenorrhea, Ginger, Premenstrual Syndrome, Walking}

\section{Conflict of Interest: No}

How to Cite: Ebrahimi Azmoudeh B, Habibian M, Askari B. The Effectiveness of the Combination of Cinnamon and Ginger with Exercise Training in the Treatment of Dysmenorrhea and Premenstrual Syndrome. Iran Journal of Nursing. 2019; 32(121):68-81.

Received: 17 Sep 2019

Accepted: 18 Dec 2019 


\title{
اثربخشى تركيب دار جين و زنجبيل همر اه با تمرينات ورزشى بر ديسمنوره و سندرم يش قاعدىى
}

\author{
بهنوش ابر اهيمى آزموده'، معصومه حبيبيان '، بابى سان عسكَرى
}

جكيده

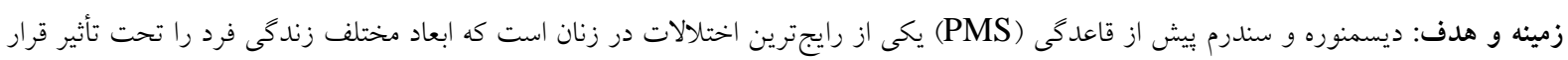

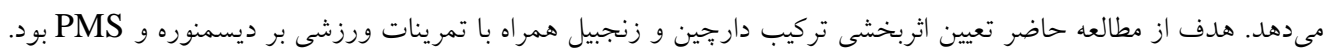

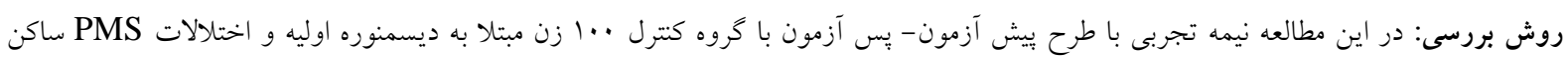

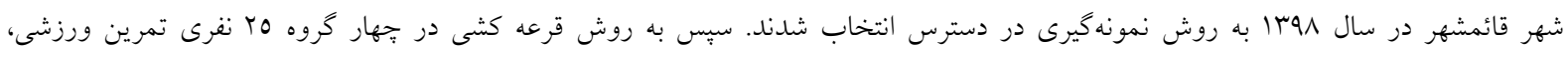

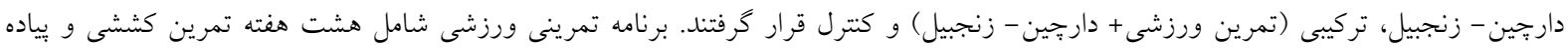

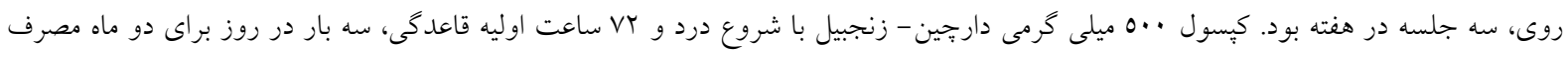

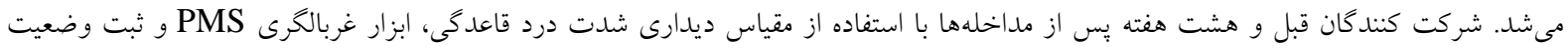

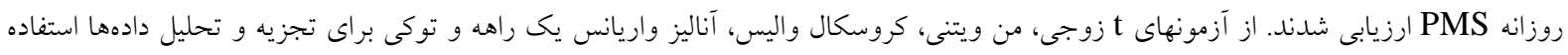

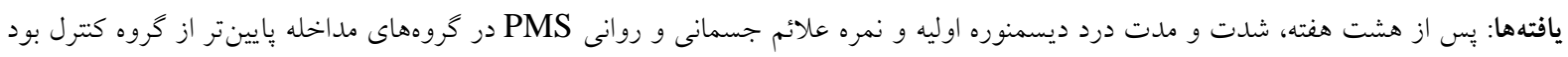

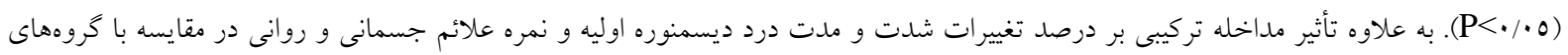
تمرين و دارجين - زنجبيل بيشتر بود.

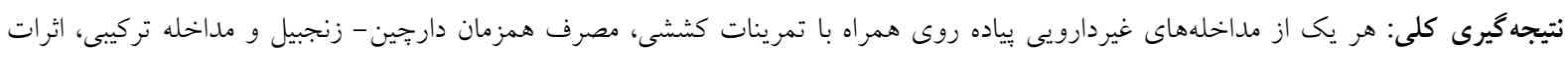

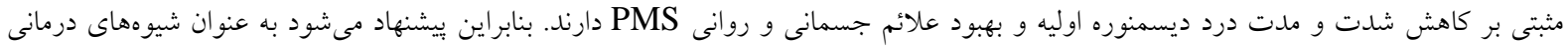

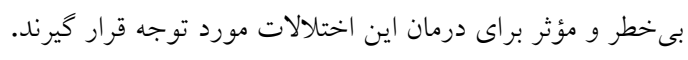

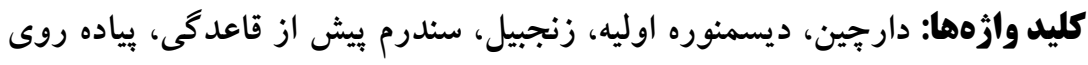

' '. كارشناس ارشد فيزيولوزى ورزش، تروه تربيت بدنى، واحد قائمشهر، دانشكاه آزاد اسلامى، قائمشهر، ايران إنان.

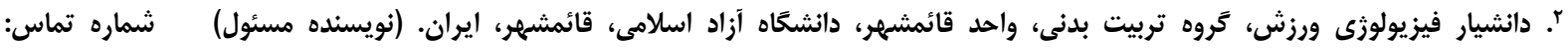




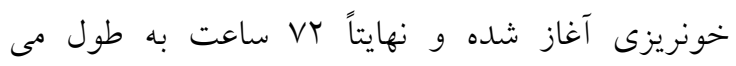

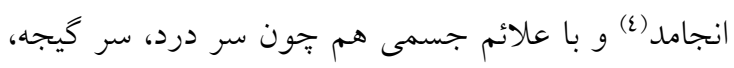

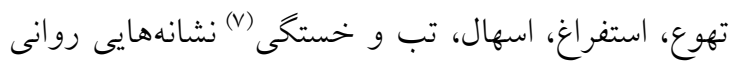

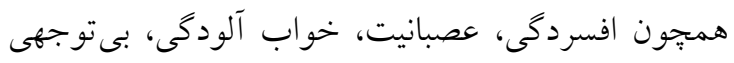

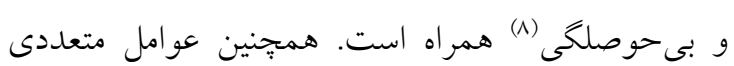

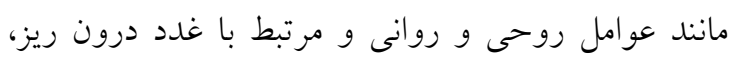

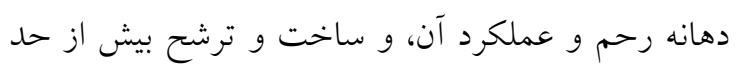

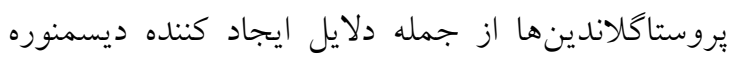

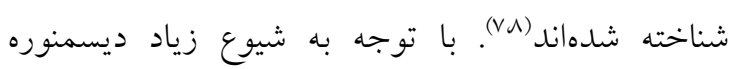

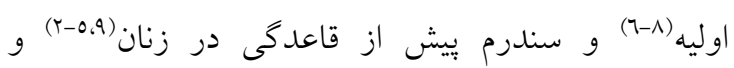

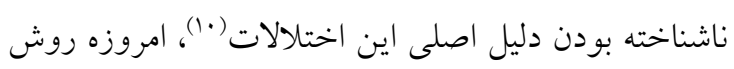

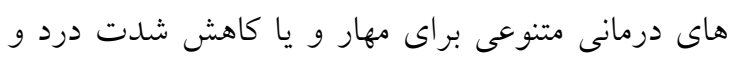

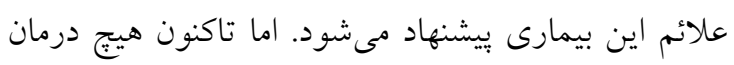
قطعى براى اين اختلالات شناخته نشده است و در موارد

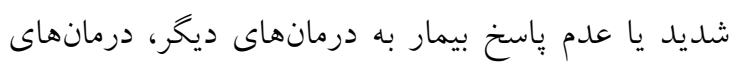

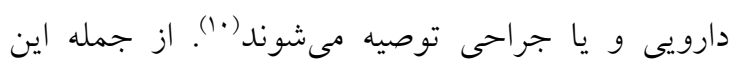
روشها استفاده از قرصهاى ضد ضد باردارى و و ساير

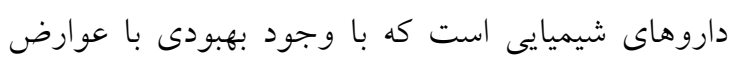
جانبى بسيارى در برخى از افراد همراه مىباشند (11). اين واين

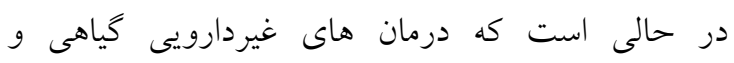
ورزشى به دليل تنوع، خطرات جانبى كمتر و به صرفه دماله

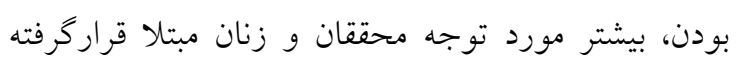

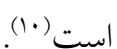
دارجين يكى از اين كياهان سنتى است كه داراى آميدون،

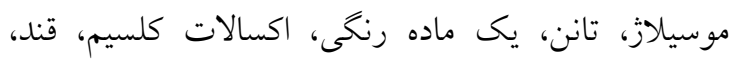

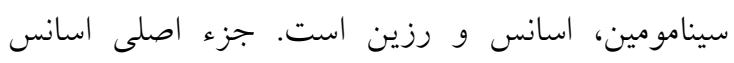
دارجين حاوى سينامالدئيد و اوزنول مىباشد، سينامالدئيد

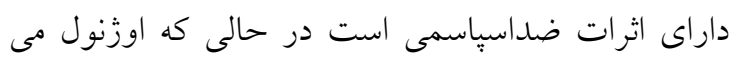
تواند با مهار بيوسنتز يروستاكلاندينها، از ميزان إنات التهاب بكاهد. تا كنون خطر به خصوصى براى مصرف دارئين

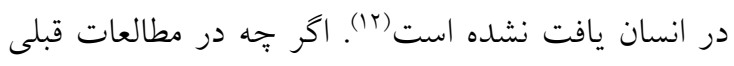

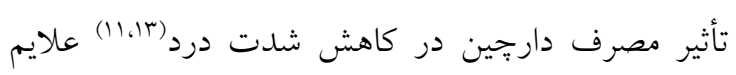

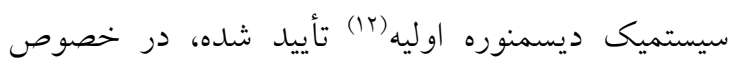
تأثير اين كياه بر علائم جسمى و روانى سندرم بيش از دئن

\section{مقدمه}

سندرم ييش از قاعدكى (Premenstrual syndrome)

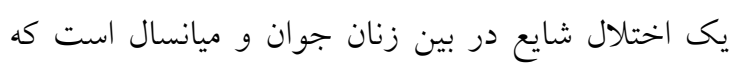

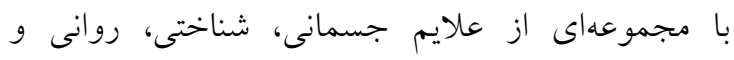

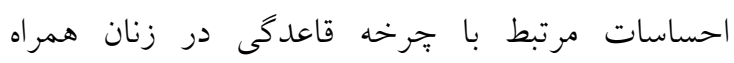

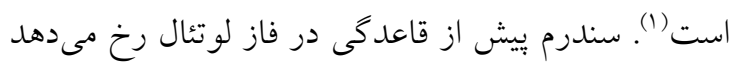

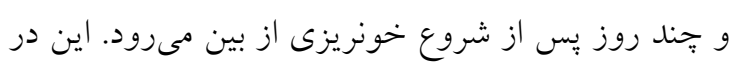

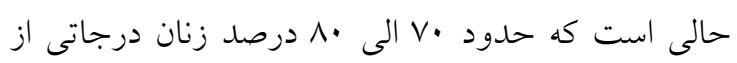

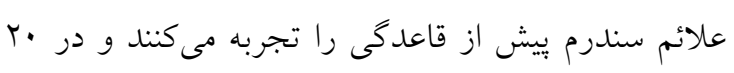

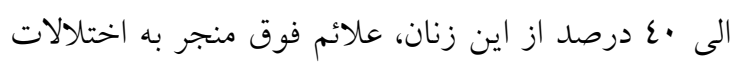

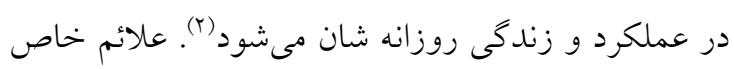

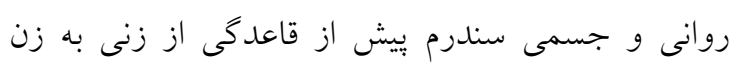

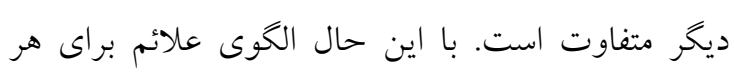

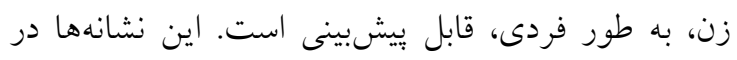

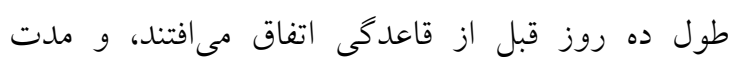
كوتاهى قبل يا بعد از شروع جريان قاعدكى نايديد

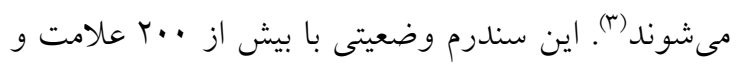
نشانه مىباشد كه اضطراب و نايايدارى هيجانى، علائم روانشناختى ضعيف، احساس نفخ شكم و اضافه وزن،

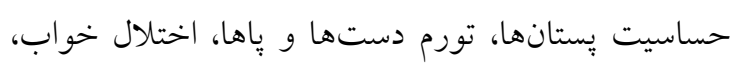

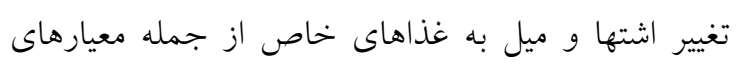

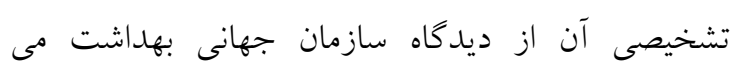

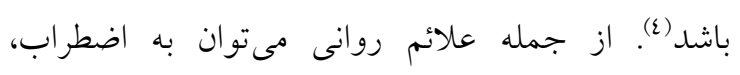

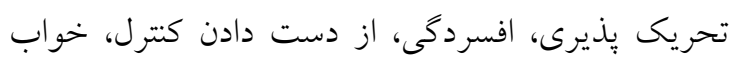

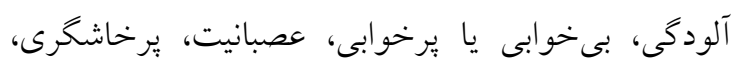

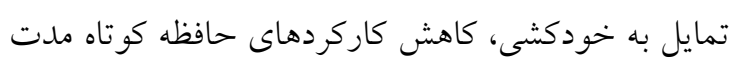
و بلندمدت، كاهش خفيف در حافظه تصويرى، زود

رنجى، بىقرارى، كيجى و گريز از اجتماع اشاره كرد (0).

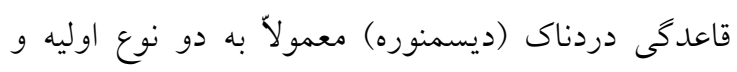

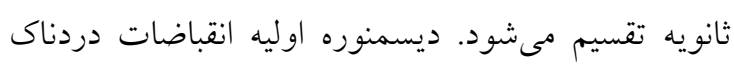

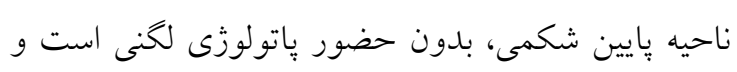

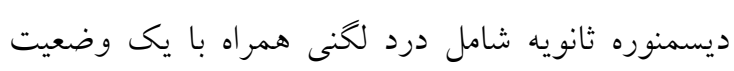
باتولوزيك مثل اندومتريوز و يا آدنوميوز مىباشد (7).

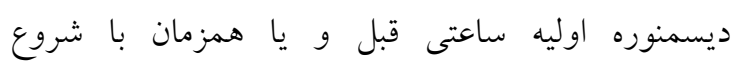


افسردىى و اضطراب در بسيارى از تحقيقات مورد

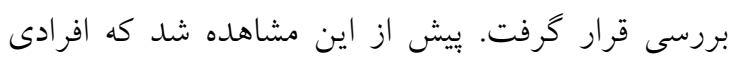

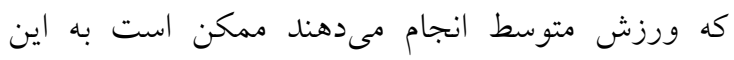

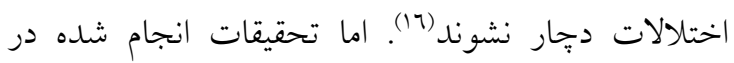

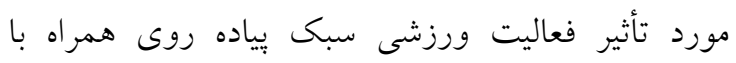
تمرينات كششى بر اختلالات قاعدگى زنان غير ورزشكار محدود است (rا) و با وجود تحقيقات گسترده در مورد

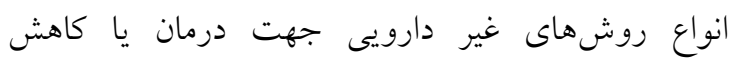
ديسمنوره اوليه يا كاهش علائم مختلف سندرم ييش از قاعدگى، هنوز هم يافتن شيوههاى جديد، آسان، ارزان،

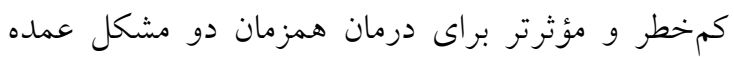

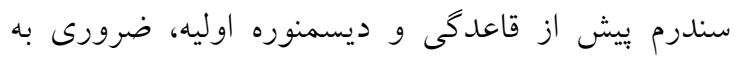

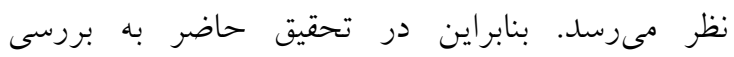

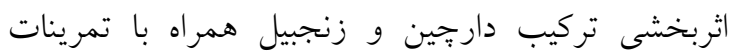

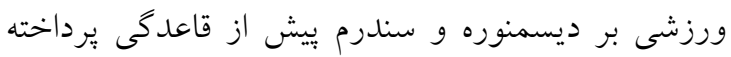

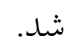

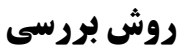

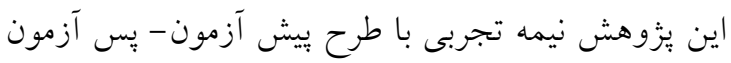

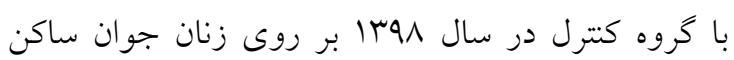
قائمشهر انجام شد. از بين داوطلبين شركت كننده در اين يزّوهش، افر ادى كه داراى دورههاى قاعدكى منظم و مبتلا

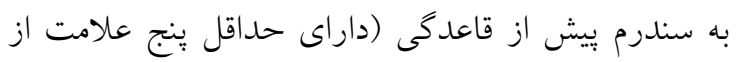

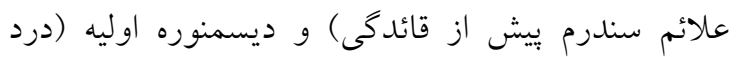

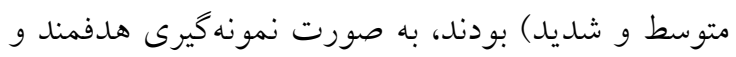
در دسترس انتخاب شدند. حجم نمونه بر اساس مطالعات قبلى، با در نظر گرفتن سطح اطمينان 90 درصد، توان

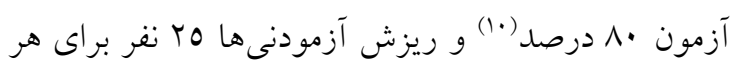

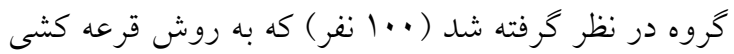
به گروههاى كتترل، تمرين ورزشى، دارجين- زنجبيل و و

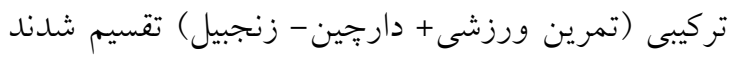

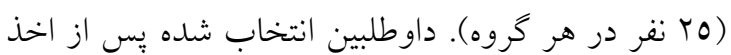
رضايت كتبى، در يُزوهش شركت نمودند. به علاوه آنها

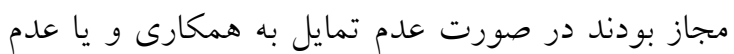

قاعدكى گزارشى مشاهده نشد است. زنجبيل نيز به عنوان

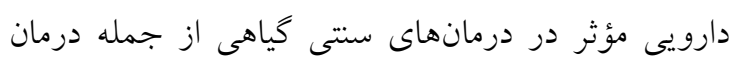

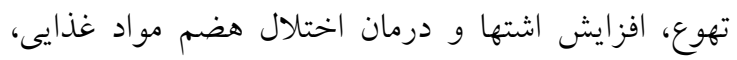

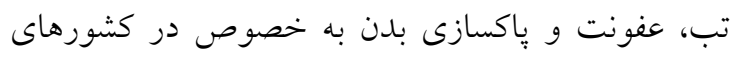

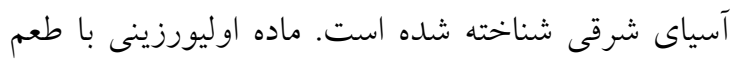

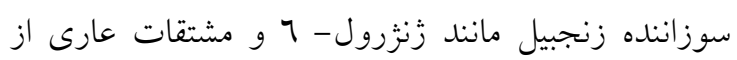
هيدروزن آن، باعث كندى و يا ممانعت از تشكيلن زتروزيل

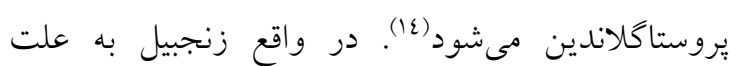

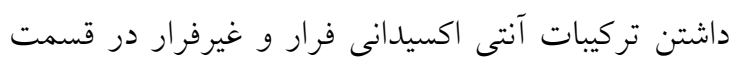

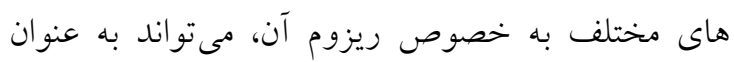

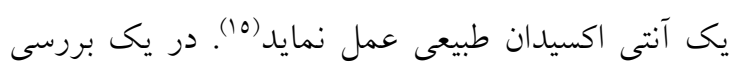

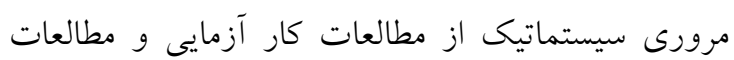

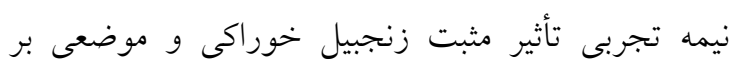

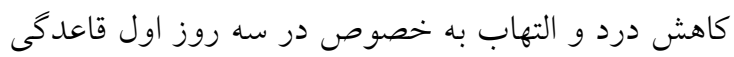

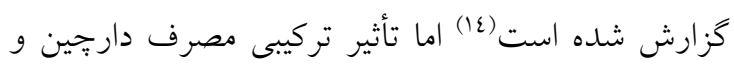
زنجبيل بر شدت درد و علائم جسمانى و روانى سندرم

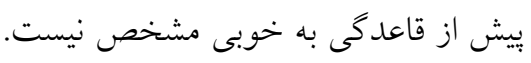

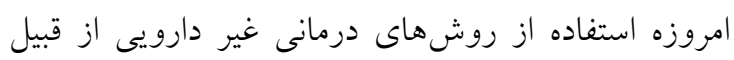

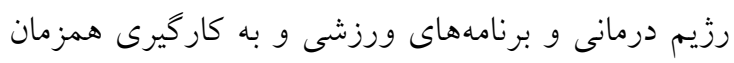

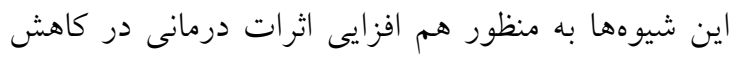
علائم سندرم يبش از قاعدى مئى و ديسمنوره اوليه مورد

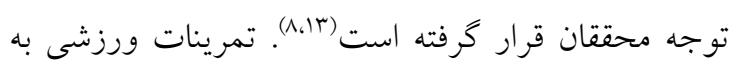

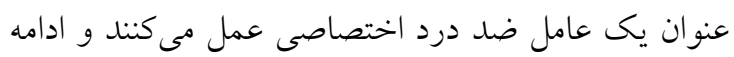

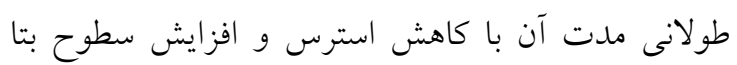

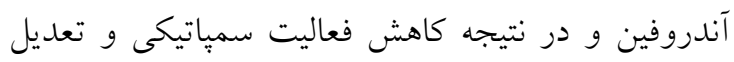

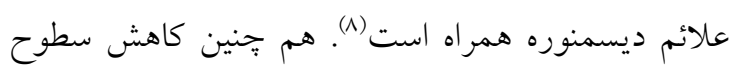

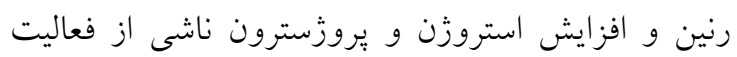

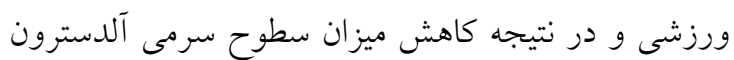

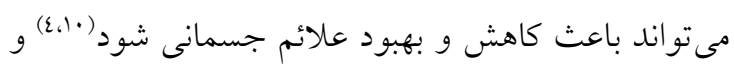

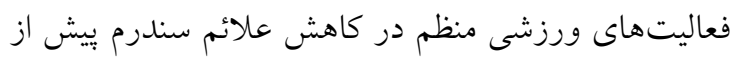

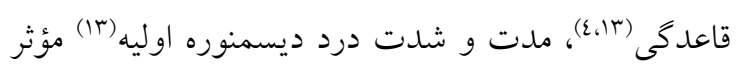
هستند (ع). از اين جهت تمرينات هوازى در بسيارى از مطالعات به عنوان خط اول درمان توصيه مىشود و اثر مثبت ورزش بر علايم عاطفى- روانى اين سندرم نظير 
جرخه قاعدگى بودند. شدت درد با استفاده از مقياس

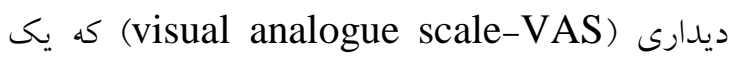
ابزار دقيق (يك خط كش • •ا سانتيمتر) براى ارزيابى

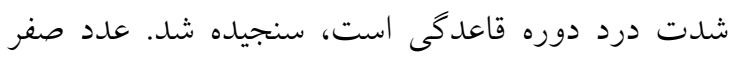

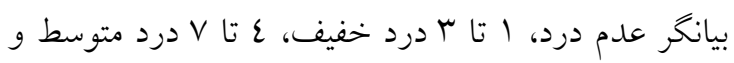

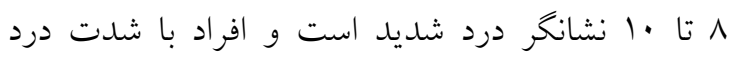
بالاتر از ع وارد مطالعه شدند (rا،|"). براى سنجش مد مدات

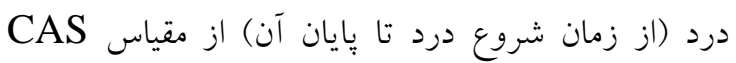
استفاده شد. بر اساس اين (Cox Menstrual Scale)

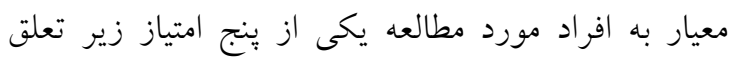
كرفت : بدون درد: امتياز صفر، درد كمتر يا مساوى نيم ساعت: امتياز يك، نيم تا مساوى يكى ساعت درد: امتياز

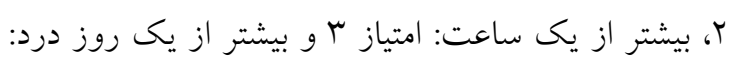

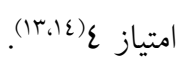

به منظور بررسى سندرم ييش از قاعدكى در آزمودنىها،

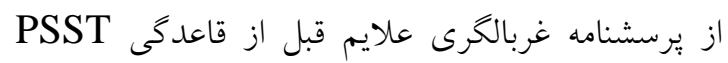

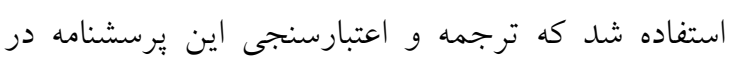
ايران براى اولين بار توسط سيه بازى و همكاران در سال

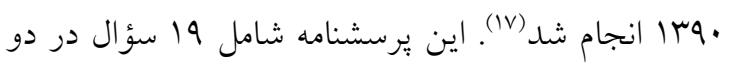

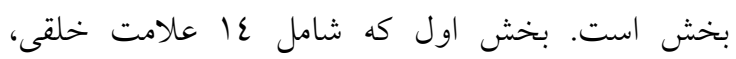
جسمى و رفتارى است و بخش دوم كه تأثير اين علائم را

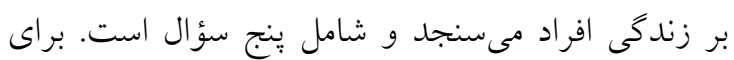

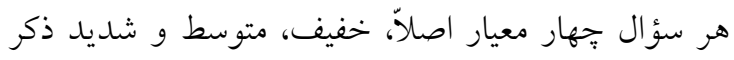

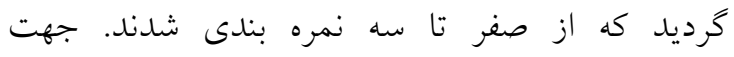

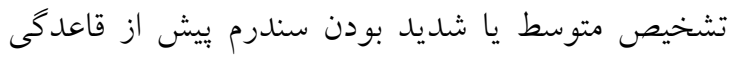
الزام وجود سه شرط ذيل و با هم در مرحله انتهايى فاز

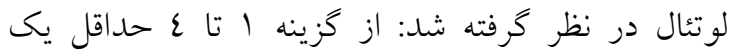
مورد متوسط يا شديد باشد؛ علاوه بر مورد قبلى از خزينه

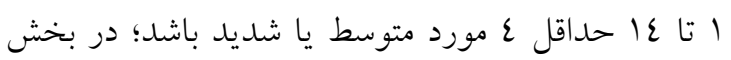

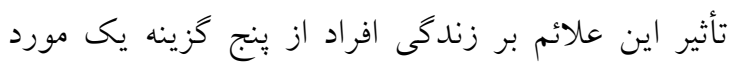

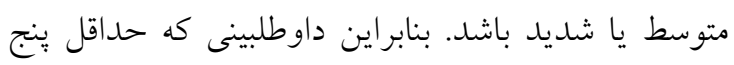

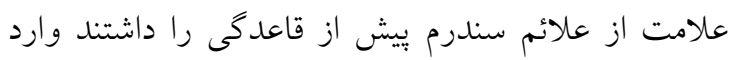

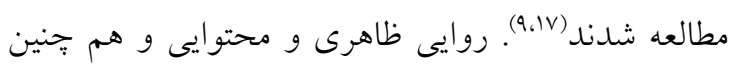
پايايى اين برسشنامه توسط محققين قبلى تأييد شده
تحمل شرايط تحقيق، از ادامه همكارى انصراف دهند.

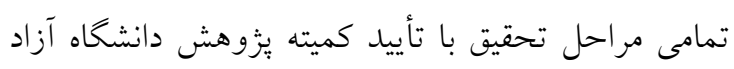

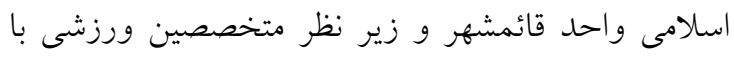

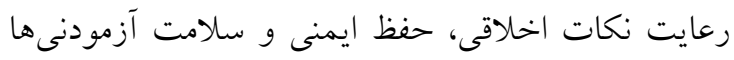

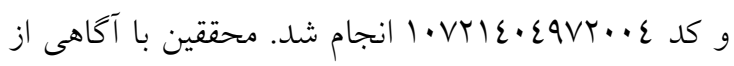

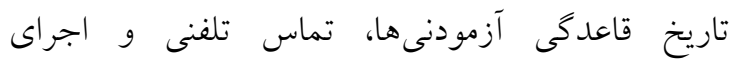

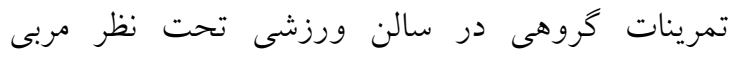

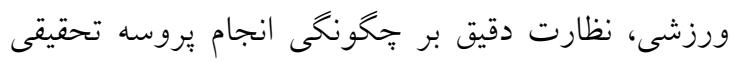
حاضر داشتند. در بايان نه نفر بنا به دلايلى از قبيل استفاده

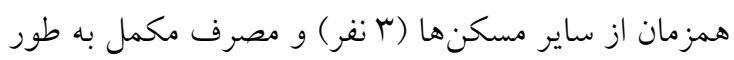

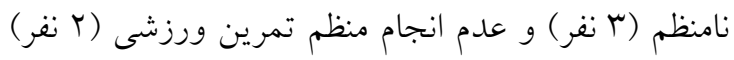

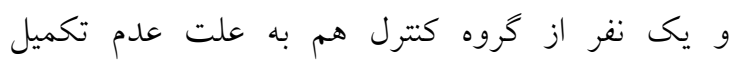
يرسشنامها، از مطالعه حذف شدند. بد بدين ترتيب تعداد

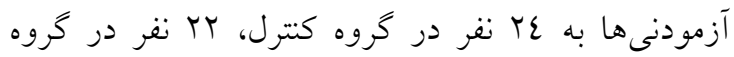

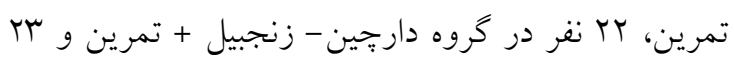
نفر در گروه دارجين - زنجبيل تقليل يافت دمرهين

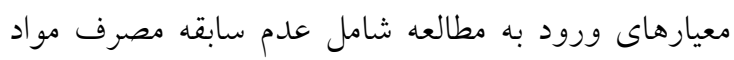

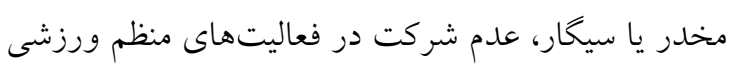

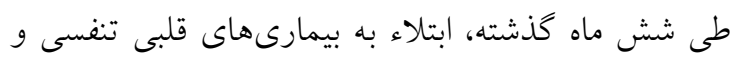
كليوى، فشار خون، آسم، ديابت، صرع، ميخرن، تيروئيد،

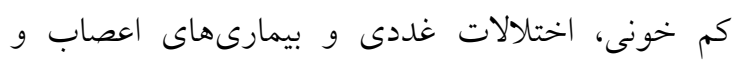

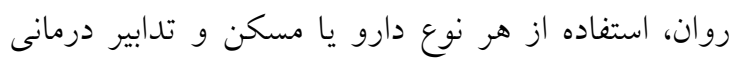

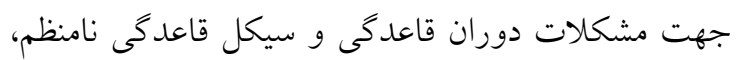
سابقه باردارى، مصرف قرصهاى ضد باردارى، عدم ابتلا به بيمارى روانى و افسردگى و شاخص توده بدنى بايين

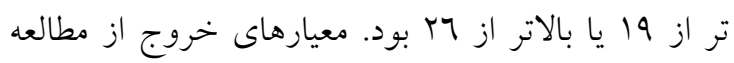
قطع مصرف مكمل و يا تمرين، مصرف داروهاى ديخر و و قاعدىى نامنظم در نظر كرفته شد.

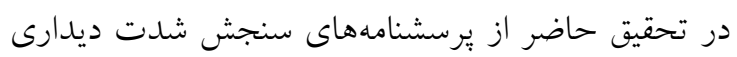
درد، مدت درد ديسمنوره و يرسشنامه غربالخرى علائم سندرم يِيش از قاعدكى (SPST) Symptoms Screening Tool روزانه استفاده شد. سئوالات فرم مشخصات جمعيت

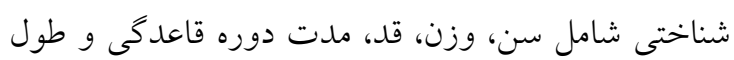


يك براى گزينه خفيف (علائم خفيف كه مانع فعاليت روزمره نشود)، امتياز دو براى كزينه متوسط (علائم متوسط كه تا حدودى در فعاليت روزمره تداخل ايجاد كند) و امتياز سه براى كزينه شديد (علائم شديد كه مانع فعاليتهاى روزمره مانند غيبت از كار و خوردن مسكن

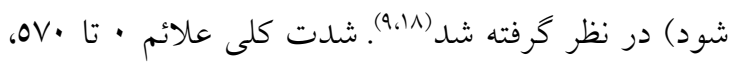

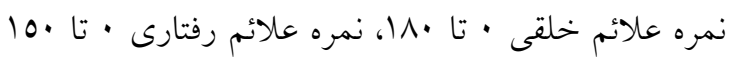

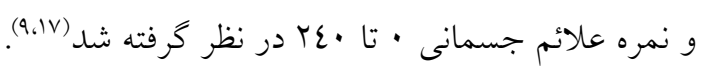

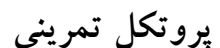

كروههاى تمرين ورزشى و تركيبى، هشت هفته تمرين

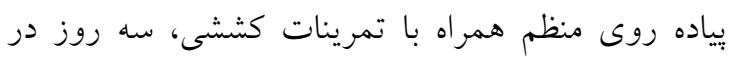

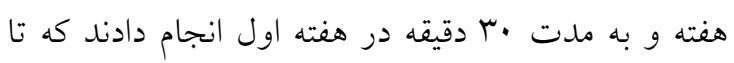
هفته هشتم به مدت مع دقيقه در هر جلسه تمرينى ادامه

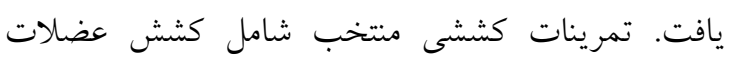
شكم، لكن و كشاله ران بود كه در هفته اول با بنج تكرار

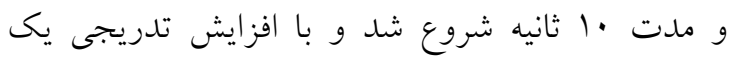

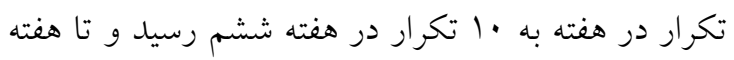
هشتم ادامه يافت (جدول شماره ()).
است (1.9.1V). سبس فرم ثبت روزانه علائم جهت تشخيص

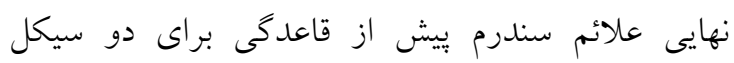

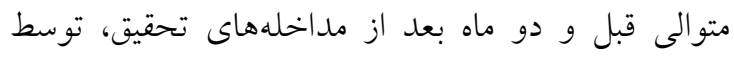

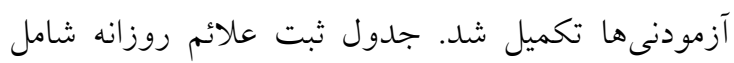
علائم خلقى (كج خلقى و بىقرارى، عصبانيت و از كوره

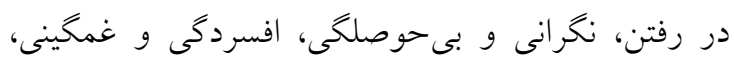

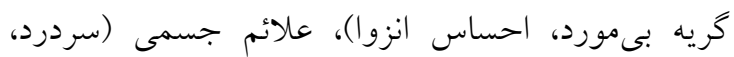

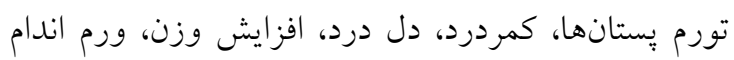
ها، درد عضلانى، علائم كوارشى و تهوع) و علائم رفتارى (احساس خستكى، كمبود انرزى، بـىخوابى، دشوارى در تمركز، اشتهاى زياد و يرخورى) بود. به هر

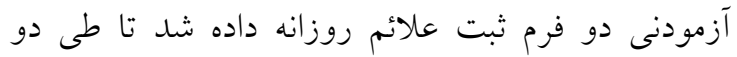

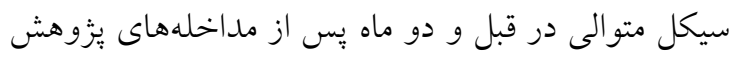

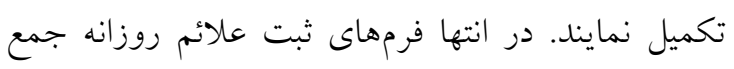

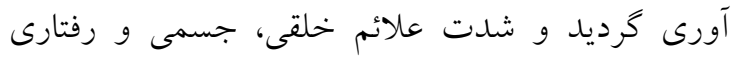
سندرم بيش از قاعدكى سه كروه قبل از مداخله و دو ماه ماه بعد از مداخلهها با هم مقايسه شد. تكى تكى امتيازات

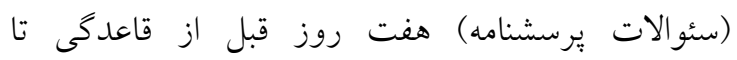

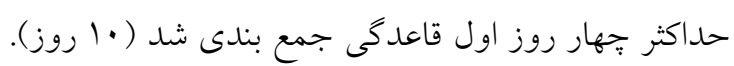

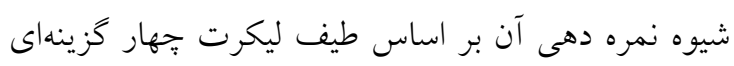
بوده كه امتياز صفر براى كزينه اصلاً (فقدان درد)، امتياز

جدول شماره (: نحوه انجام تمرينات كششى

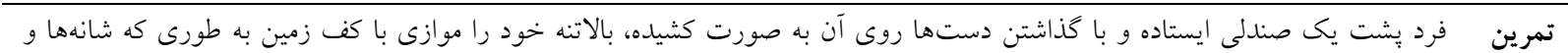

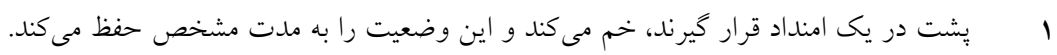

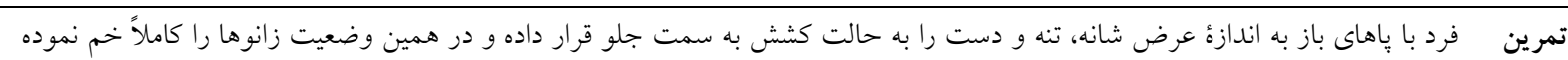

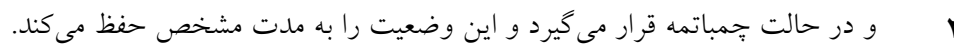

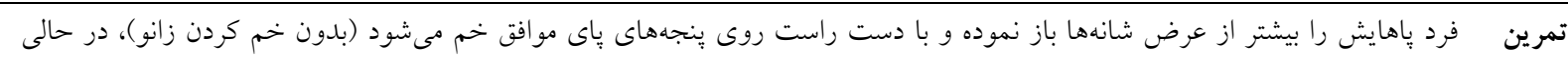

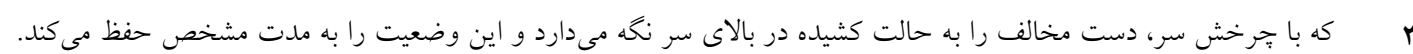

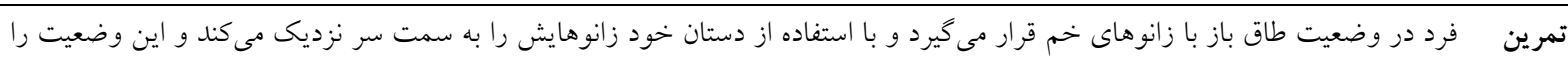

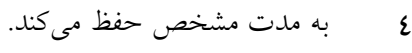

تمرين فرد در وضعيت طاق باز با زانوهاى خم و دستها در دو طرف بدن، روى زمين قرار مى گيرد.سبس بِاها را به اندازه عرض شانهها باز كرده

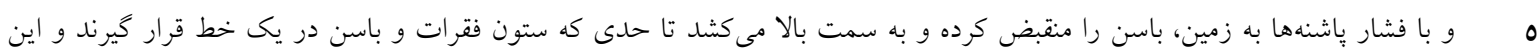

وضعيت را به مدت مشخص حفظ مى كند.

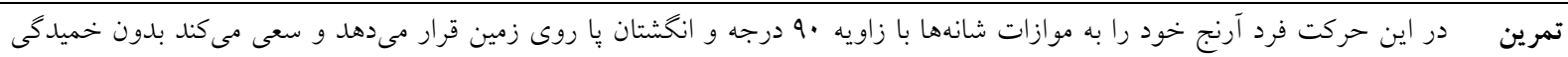
باسن و زانو با يشت صاف، ستون فقرات در حالت خنتى نخه دارد و اين انقباض را رِ حفظ نمايد. 
از آزمونهاى اسميرنوف - كلموكروف و لوين به ترتيب

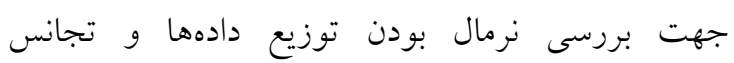

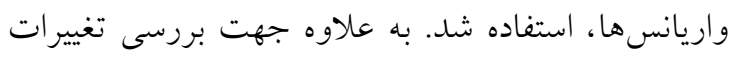
درون كروهى از آزمون t زوجى (ويلكاكسون براى داده بها

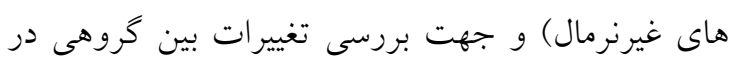

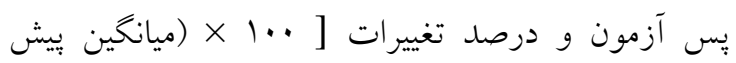

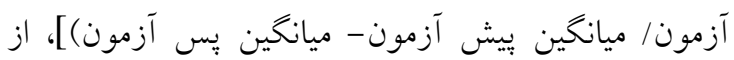

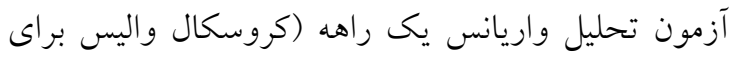
دادههاى غيرنرمال) استفاده شد و در صورت مشاهده معنى دارى اختلاف بين گروهها، براى تعيين محل اختلاف

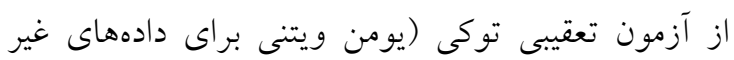

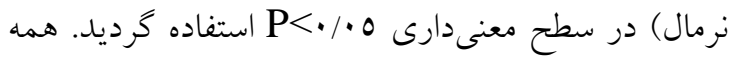

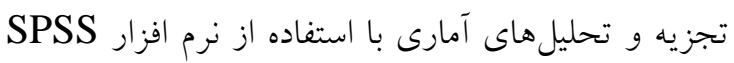
نسخه 17 انجام شد.

\section{يافتهها}

ميانخين و انحراف معيار ويزگكىهاى آزمودنىها در وضعيت پايه در جدول شمارهى r نشان داده شده است.

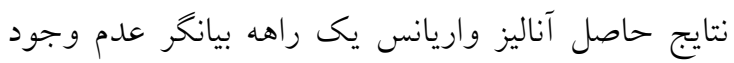

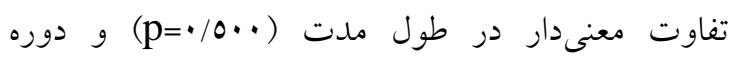

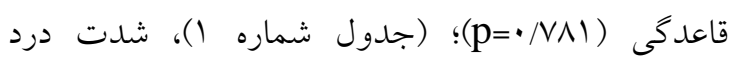
(P=•/07•)

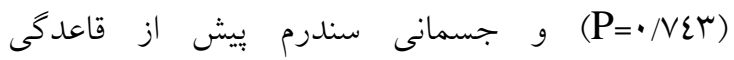
و مدت درد (P=•/AVq)

$$
\text { كروسكال واليس) در وضعيت بِايه بود. }
$$

برنامه يياده روى نيز شامل ينج دوره متناوب از كامهاى

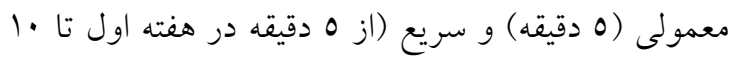
الى 10 دقيقه در هفته هشتم) به مدت TO TOت دقيقه در هفته اول بود و تا ro الى مع دقيقه در هفته هشتم انجام شد. هدف از انجام اين تمرينات تقويت عضلات ناحيه لكنى

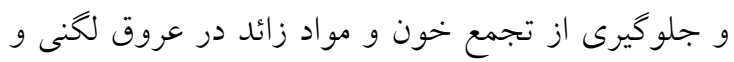

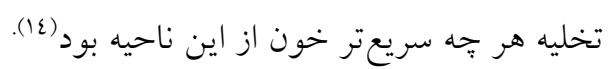
مكمل تركيبى دارجين - زنجبيل كيسول ل.0 ميلى كرمى حاوى مقادير مساوى يودر دارجين و زنجبيل كه به صورت دو سوكور در اختيار

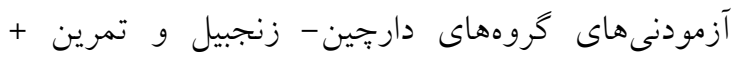

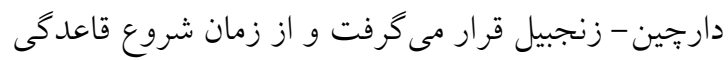

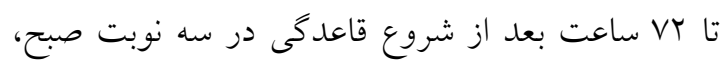
ظهر و شب همراه با وعدههاى غذايى اصلى (يكى عدد در هر نوبت) طى دو سيكل متوالى مصرف مىنمودند. كروه

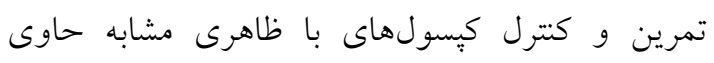

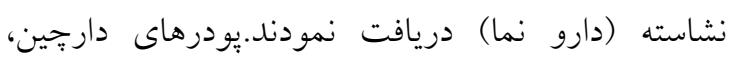
زنجبيل و نشاسته با سفارش قبلى توسط يكى از مراكز معتبر تهيه و فروش كياهان دارويى شهر تهيه و به ميزان دقيق در كيسولهاى مشابه كنجانده شد. از مهمترين موارد دستورالعمل تغذيهاى بود كه براى يكسان سازى ده دهابه

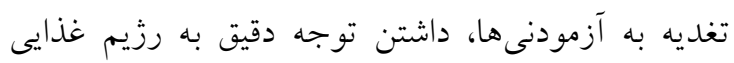

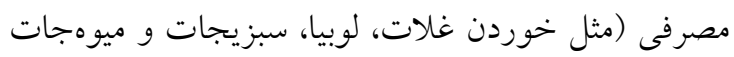
كم خوردن يا نخوردن نمك، كافئين و مواد قندى)

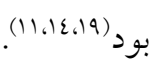
جدول شماره ז: مقايسه ويزَّى هاى مشاركت كندَّان بر حسب شاخص هاى مركزى و انحراف استاندارد قبل از مداخله

\begin{tabular}{|c|c|c|c|c|c|c|}
\hline قائدگى (روز دوره & قاعدگى (روز) مدت & $\begin{array}{c}\text { BMI } \\
\text { (كيلو كرم/ مترمربع) }\end{array}$ & سن (سال) & (كيلو مرم) & (سانتى متر ) & كروه \\
\hline$\langle N / \cdot \Lambda \pm 1 / 77$ & $7 / 1 V \pm 1 / 77$ & $r^{T} / 01 \pm 1 / \cdot \varepsilon$ & $r T / O \Lambda \pm 1 / \varepsilon r$ & $7 \cdot / \Lambda \Psi^{\prime} \pm / 20$ & $17 . / 7 V \pm \varepsilon / \Lambda 1$ & كنترل \\
\hline$Y N / Y I \pm 1 / T V$ & $0 / 0 r \pm 1 / \varepsilon$. & $r Y / A r \pm \cdot / 9$. & $r r / 90 \pm 0 / r T$ & $0 / / I V \pm 0 / 10$ & $109 / 79 \pm 0 / 91$ & دارجين - زنجبيل - \\
\hline$Y N / T V \pm 1 / 70$ & $O N r \pm 1 / T \Lambda$ & $r r / \Lambda \cdot \pm r / M r$ & $r Y / T O \pm Y / O \varepsilon$ & $\Delta q / 0 v \pm \varepsilon / \Lambda 1$ & $171 / 09 \pm 7 / \cdot 7$ & تمرين ورزشى \\
\hline$T N / 0 \cdot \pm 1 / 77$ & $7 / \pi 7 \pm 1 / 10$ & $r r / .0 \pm \cdot / 9 r$ & $r r / \cdots \pm 1 / r \varepsilon$ & $09 / 20 \pm 0 / 2$. & $\mid 7 \cdot / 21 \pm 0 /$ Vo & 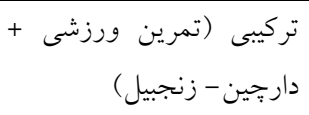 \\
\hline$\cdot \pi$ & . NQE &.$/ 179$ & $1 / N N 1$ &.$/ 90 r$ & $.10 \mathrm{Va}$ & FF F F F \\
\hline . NAI & $\cdot / 0 .$. &.$/ 91 \mathrm{~V}$ &.$/ 10 \mathrm{~V}$ & $\cdot / 219$ & • זר/. & P*" ارزش \\
\hline
\end{tabular}

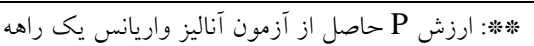




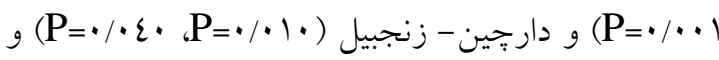

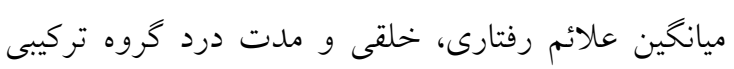

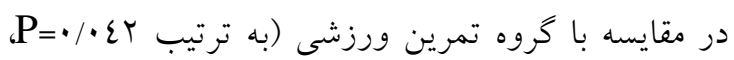

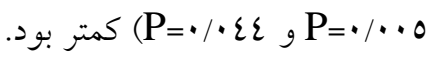

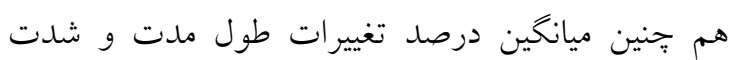

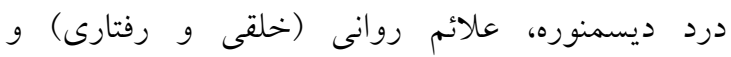

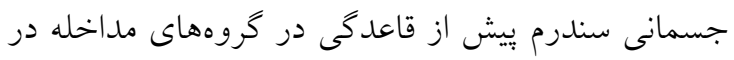
مقايسه با كروه كنترل (P</0)

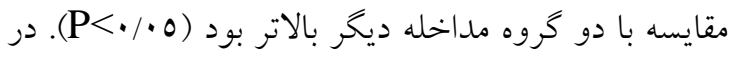

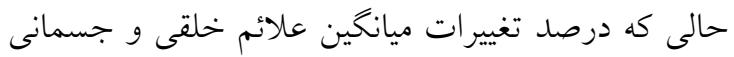

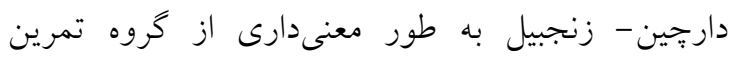

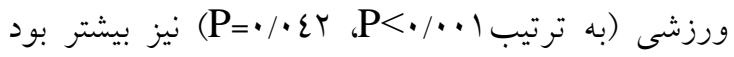

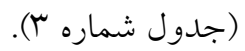

نتايج مقايسههاى درون گروهى نشان داد كه بِ از هشت

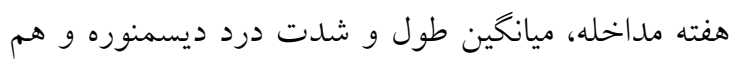
خنين علائم روانى (خلقى و رفتارى) و جسمانى سندرم

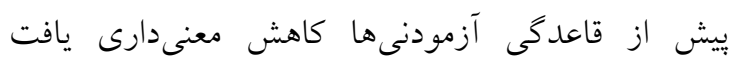
$(\mathrm{P}<\cdot / \cdots 1)$

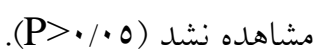

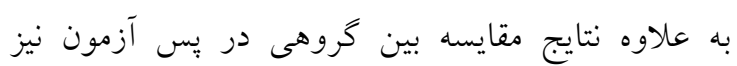

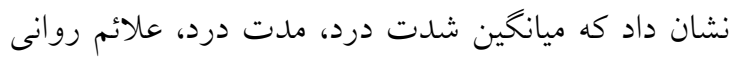

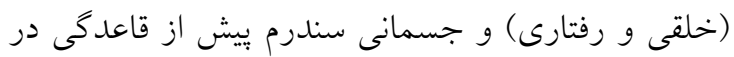

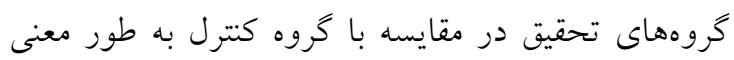

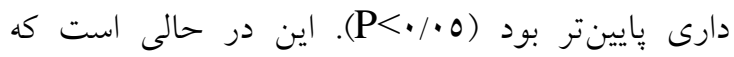
ميانخين علائم جسمانى و شدت درد در كروه تركيبى در

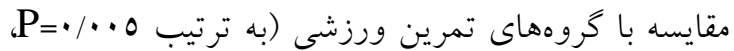

جدول شماره "اّ: مقايسه ميانكَين و انحراف استاندارد متغيرهاى تروههاى تحقيق در بيش و 1 هفته بس از مداخله

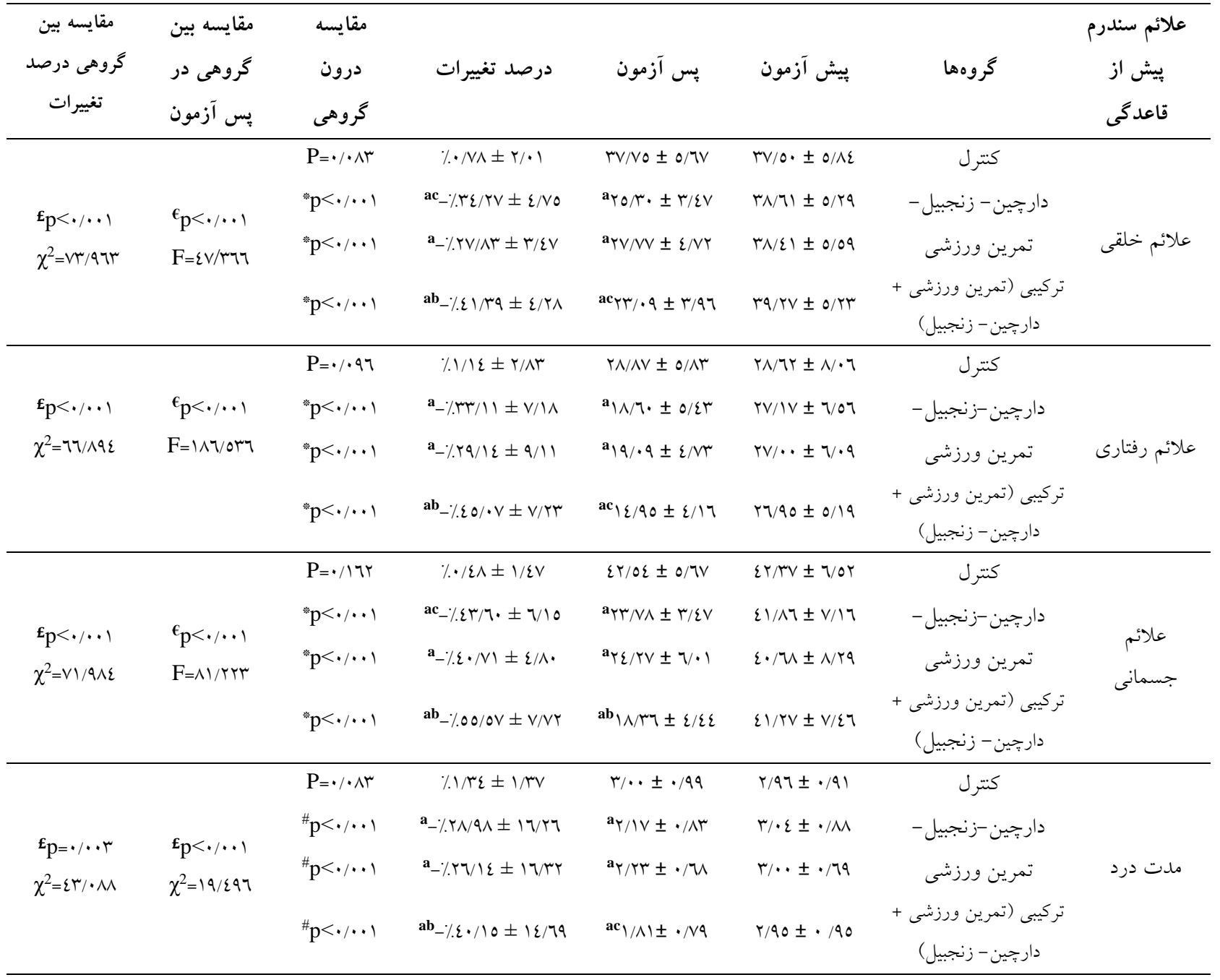




\begin{tabular}{|c|c|c|c|c|c|c|c|}
\hline & & $\mathrm{P}=\cdot / 700$ & $\% r / r 7 \pm 0 / .9$ & $V / T Y \pm \cdot / 91$ & $V / \cdot v \pm 1 / \cdot 1$ & كتترل & \\
\hline$\epsilon_{\mathrm{p}}<\cdot / \cdot \cdot 1$ & $\epsilon_{\mathrm{p}}<\cdot / \cdot \cdot 1$ & $" \mathrm{p}<<\cdot / \cdot+1$ & $a_{-}-\varepsilon \varepsilon \varepsilon / u \pm \Lambda / 0 \Lambda$ & $a_{\Gamma / V \Lambda} \pm \cdot / \Lambda \Lambda$ & $\mathrm{T} / \mathrm{V} \wedge \pm \cdot / \mathrm{A} 1$ & دارجين - زنجبيل - & \\
\hline \multirow[t]{2}{*}{$\mathrm{F}=r T V / \Omega 00$} & $F=111 / 29$. & $" \mathrm{p}<\bullet / \cdot \cdot 1$ & a $\_/ r q / \wedge r \pm r / q r$ & $a_{\mathcal{L} / T O \pm \cdot / \wedge}$. & $V / \cdot r \pm \cdot / V q$ & تمرين ورزشى & شدت درد \\
\hline & & $" \mathrm{p}<\bullet \cdot \cdots 1$ & 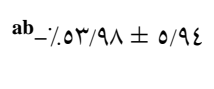 & $a b_{\Gamma / / \varepsilon \pm \cdot / 79}$ & $V W D \pm \cdot / 99$ & تركيبى (تمرين ورزشى + & \\
\hline
\end{tabular}

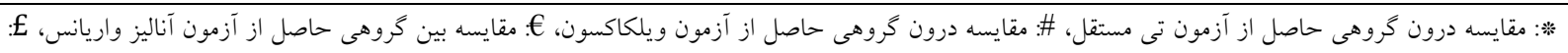

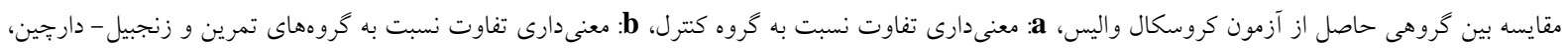

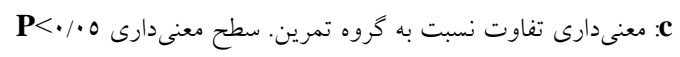

و مدت درد ديسمنوره و كاهش ميزان مصرف دارو

متعاقب هشت هفته تمرينات هوازى و يا تمرين يو گا(Y)؛

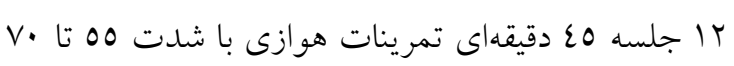

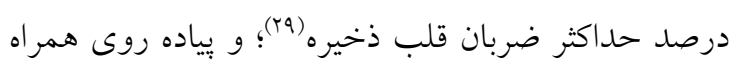
با تمرينات كششى(rا) نيز مشاهده شده است. بنابراين فعاليت بلنى ممكن است به علت اثربخشى بر شدت درد

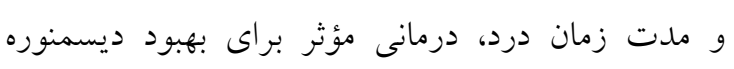
اوليه(·) و كاهش علائم جسمانى و روانى سندرم بيش از

$$
\text { قاعدگى محسوب شود. }
$$

اكر جهه نتيجه كاهش جريان خون متعاقب انقباضات بيش از حد رحم و عروق آن، از جمله دلايل اصلى درد

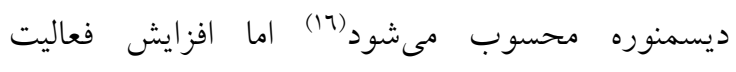
اعصاب سمياتيك ناشى از استرس نيز ممكن است با تشديد انقباض عضلات رحمى، شدت درد قاعدگى را

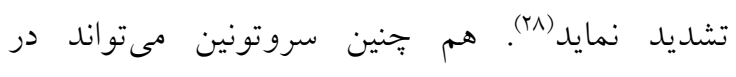
باتوفيزيولوزى سندرم يِيش از قاعدگى دخيل باشد و نقش مهمى در تنظيم خلق و خو و خصومت و خشم، و

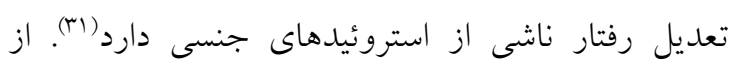
طرفى استروزن توليد شده از بافتهاى جربى مىتواند باعث تغييرات عاطفى و روانى شود (ع). اكر جّه مكانيزم دقيق تأثير ورزش بر شدت و مدت ديسمنوره و علائم سندرم بيش از قاعدكى به خوبى شناخته نشده است ولى ورئ محققين نشان دادند كه تمرينات كششى با افزايش جريان خون لخنى و كاهش تجمع بروستاگلالدين در اين ناحيه، منجر به تأخير شروع درد مى گردد(ז'). به نظر مىرسد اجراى فعاليت منظم ورزشى با كاهش اختلالات مربوط به ميانجى گرهاى عصبى به ويزه سروتونين و كاما در مطالعه حاضر نتايج نشان داد كه طول مدت ون و شدت درد ديسمنوره و علائم جسمانى و روانى (خلقى و رفتارى) سندرم بيش از قاعدكى متعاقب هشت هفته يِياده روى همراه با تمرينات كششى، مصرف دارجين و تركيبى

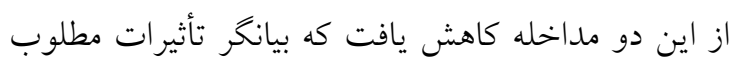
هر يك از اين مداخلهها بر كاهش شدت ود دو درد ديسمنوره

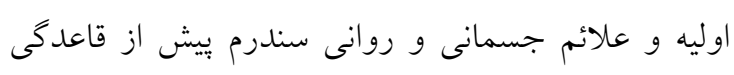
در زنان جوان غيرفعال است. نتايج تحقيقات قبلى حاكى از شيوع بالاى ديسمنوره در دختران دانش آموزان نوجوان

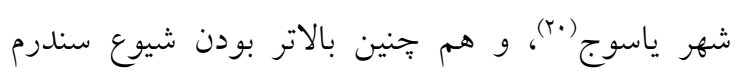

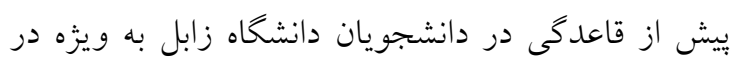
افرادى باشاخص توده بلدى بالاتر ار مO كيلوگرم/ متر مربع (Yl) و درد بيشتر در زنان غيرفعال در مقايسه با زنان

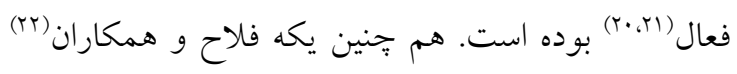
هم بيان داشتند سه ماه يِياده روى سريع و يا تمرينات روزانه هوازى (به مدت •ب دقيقه) منجر به كاهش در احساس درد، علائم جسمانى و روانى ناشى از سندرم بيش از قاعدكى در دانشجويان جوان \1 تا بم ساله دانشخاه علوم يزشكى قزوين شد. مشابه با نتايج تحقيق حاضر، كاهش علائم جسمانى و روانى - رفتارى سندرم بيش از قاعدگى متعاقب هشت هفته تمرين ورزشى

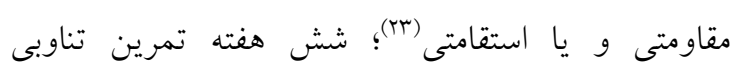

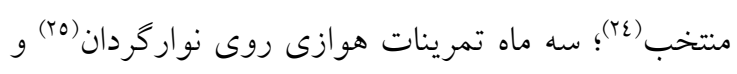
كاهش شدت علائم جسمانى يس از هشت هفته تمرين

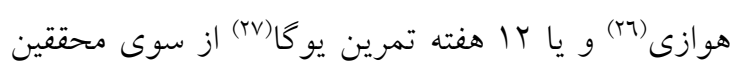
ديخر گزارش شده است. به علاوه كاهش معنىدار شدت 
ديسمنوره و علائم سندرم بيش از قاعدكى اعمال نمايد.

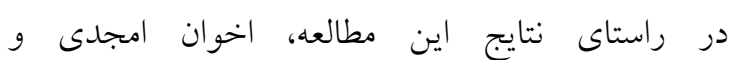

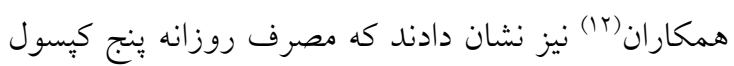
ط r.

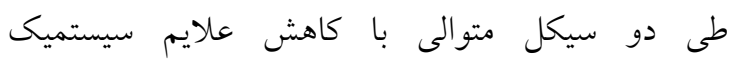

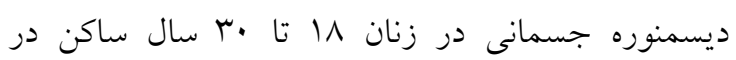

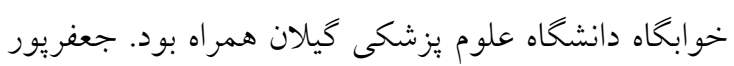

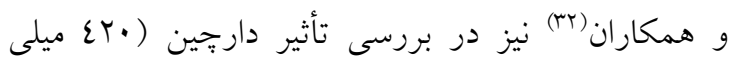
كرم) و ايبويروفن جهت درمان ديسمنوره مشاهده نمودند

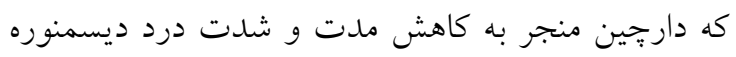
شد، اما اين اثرات در مقايسه با ايبويروفن كمتر بود.

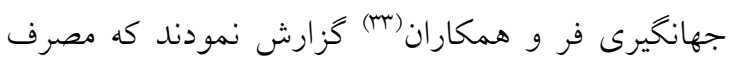

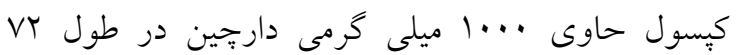

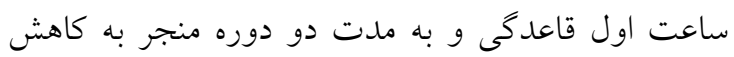
شدت درد ديسمنوره مىشود. از سوى ديخر رهنما و

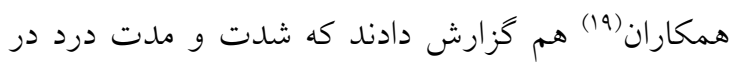

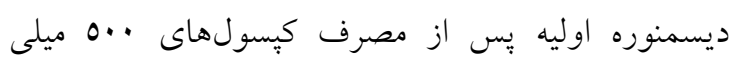

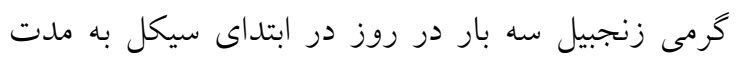

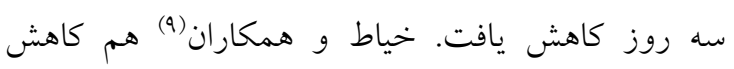

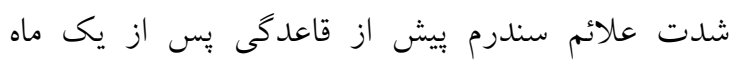

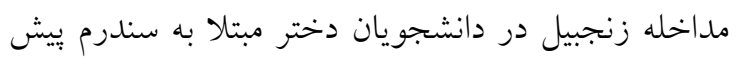

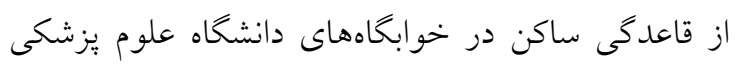

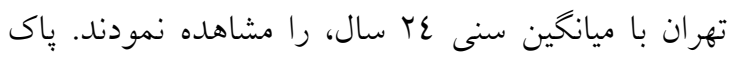

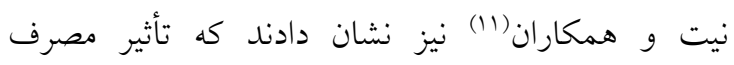
زنجبيل همراه با مفناميك اسيد بر كاهش درد ديسمنوره بيشتر از درمان دارويى صرف مفناميك اسيد در

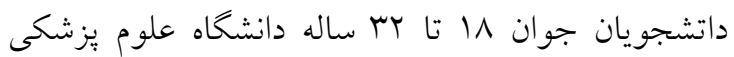
قزوين بوده است. اكر جهه در تحقيق حاضر تأثير مداخلههاى دارجين و ويا زنجبيل با و يا بدون فعاليت ورزشى به دليل افزايش

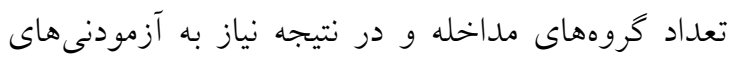
بيشتر مورد بررسى قرار نخرفت كه از جمله محدوديت

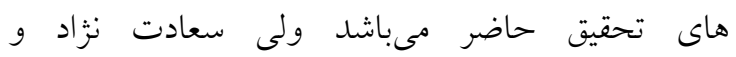
همكاران(^) نشان دادند مصرف زنجبيل، تمرين مقاومتى و
آمينوبوتيريك، كاهش استرس، توسعه كردش خون،

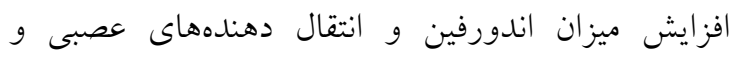

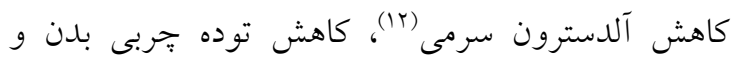
كاهش ميزان استروزن به عنوان يكى از عوامل تغييرات

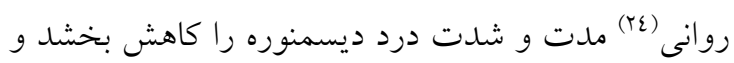
منجر به بهبود علائم سندرم ييش از قاعدكى (9) شود.

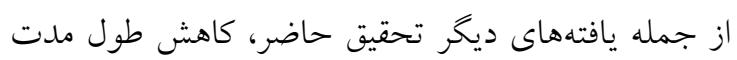

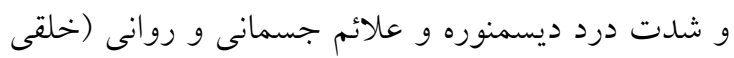

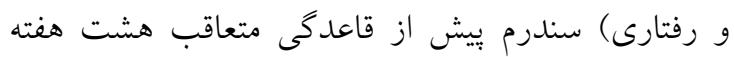
مصرف تركيبى از دارجين- زنجبيل بود كه اين تغييرات همراه با انجام تمرينات ورزشى تشديد كرديد. زنجبيل متابوليسم اسيد اراشيدونيك را مهار مى كند و اثر ضد لهد التهابى ايجاد مىنمايد. اثر ضد التهاب زنجبيل ناشى از

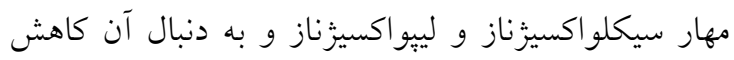

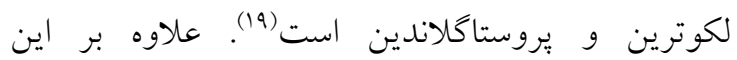

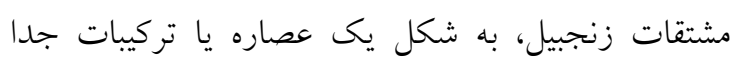

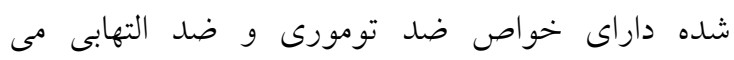

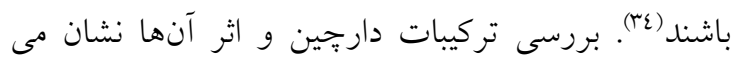

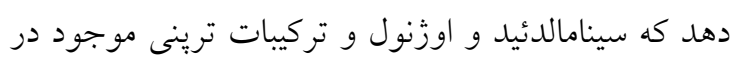

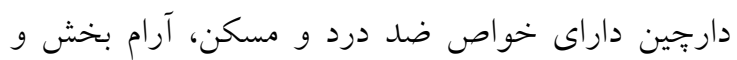

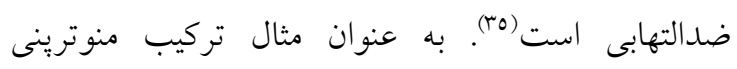

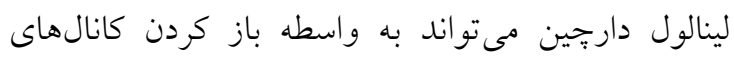

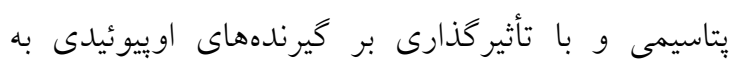
ترتيب سبب ايجاد يّانسيل مهارى در نورونهاى سيستم عصبى مركزى و اثرات ضد دردى شود (ج"). دارجين از

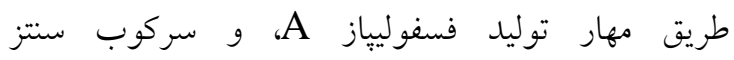

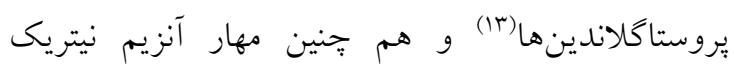
اكسايد سنتاز از ايجاد نيتريك اكسايد در محل التهاب جلو گيرى كرده و از اين طريق مىتواند منجر به اثرات ضد التهابى كردد. توليد نيتريك اكسايد در محل التهاب باعث كشاد شدن موضعى عروق و در نتيجه افزايش خيز

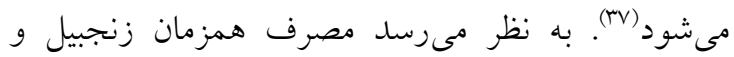

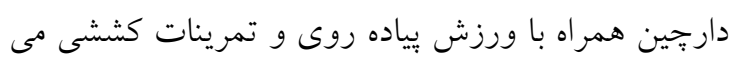

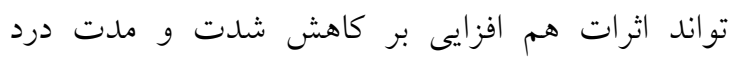




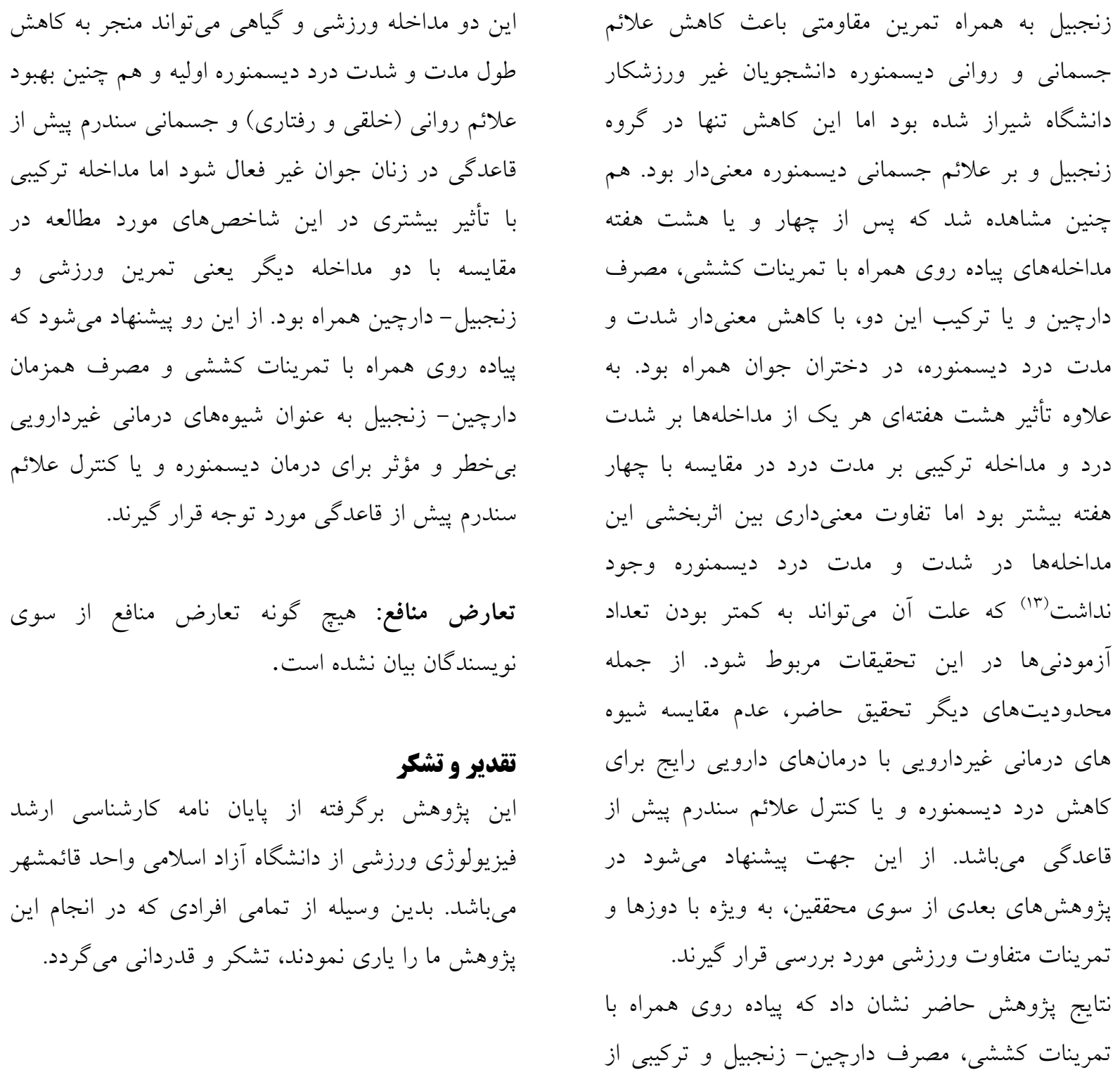

\section{References}

1- Hannani S, Ghanbary Nekoo N, Nasiri Ziba F, Hosseini AF. The Prevalence of Premenstrual Syndrome and Its Influential Factors in Operating Room Technologists. Iran Journal of Nursing. 2019;32(118):62-71. [Persian]

2- Moradi M. Assessment of the effects of massage therapy on premenstrual syndrome. Zahedan Journal of Research in Medical Sciences. 2011;13(2): 38-43. [Persian]

3- Eshaghi M, Falah R, Emamgholi Khooshehchin T, Hasani J. The effect of stress management group counseling on the symptoms of premenstrual syndrome. Journal of hayat. 2018;23(4):35871. [Persian]

4- Salehi F, Marefati H, Arabpour S, Modares Nejad V. Comparison of premenstrual syndrome status and primary dysmenorrheal in active and non-active students. The Iranian Journal of Obstetrics, Gynecology and Infertility. 2012;15(10):21-9. [Persian]

5- Forrester-Knauss C, Stutz EZ, Weiss C, Tschudin S. The interrelation between premenstrual syndrome and major depression: results from a population-based sample. BMC Public Health. 2011;11(1):795.

6- Ju H, Jones M, Mishra G. The prevalence and risk factors of dysmenorrhea. Epidemiol Rev. 2014;36(1):104-13. 
7- Saei Gharenaz M, Ozgoli G. Effect of medicinal plants in the treatment of primary dysmenorrhea in Iran: a review article. The Iranian Journal of Obstetrics, Gynecology and Infertility. 2015;18(160):14-31. [Persian]

8- Koushkie Jahromi M, Salesi M. Comparison ginger and resistance training on primary dysmenorrhea in female students of Shiraz university. ISMJ. 2015;18(1):100-9. [Persian]

9- Khayat S, Kheirkhah M, Behboodi Moghadam Z, Fanaei H, Kasaeian A, Javadimehr M. Effect of treatment with ginger on the severity of premenstrual syndrome symptoms. ISRN obstetrics and gynecology. 2014;2014:1-5.

10- Valiani M. Comparison the Effects of aerobic exercise and vitamin b6 in severity of symptoms of premenstrual syndrome in non-athlete girls. Complementary Medicine Journal of faculty of Nursing \& Midwifery. 2013;3(3):552-62. [Persian]

11- Pakniat H, Hajiseyed Javadi ES, Golmohammadi Z, Ashrafi M. The Effect of Ginger on Primary Dysmenorrhea in Students of Qazvin University of Medical Sciences. Journal of Medicinal Plants. 2019;2(72):98-106. [Persian]

12- Akhavan Amjadi M, Mojab F, Shagbazzadegan S. Efficacy of cinnamomum zeylanicum on primary dysmenorrhea and systemic symptom of it on the students of Gilan university of medical sciences 2007. Journal of Ardabil University of Medical Sciences. 2009;9(3):204-9. [Persian]

13- Habibian M, Safarzadeh Z. Comparison of the effectiveness of walking assotiated with stretching exercises and cinnamon In take on the primary dysmenorrhea. Razi Journal of Medical Sciences. 2018;25(171):11-9. [Persian]

14- Mozafari S, Saei Ghare Naz M, Ozgoli G. Effect of Ginger on primary Dysmenorrhea: A systematic review of clinical trials and Quasi-Experimental studies in the world. The Iranian Journal of Obstetrics, Gynecology and Infertility. 2018;21(Supple):86-93. [Persian]

15- Grzanna R, Lindmark L, Frondoza CG. Ginger-an herbal medicinal product with broad antiinflammatory actions. J Med Food. 2005;8(2):125-32.

16- Mohammadi B, Azamian Jazi A, Fathollahi Shourabeh F. The effect of aerobic exercise training and detraining on some of the menstrual disorders in non-athlete students in Lorestan Universities. The Horizon of Medical Sciences. 2012;18(2):5-12. [Persian]

17- Siahbazi S, Hariri FZ, Montazeri A, Banaem LM. Translation and psychometric properties of the Iranian version of the Premenstrual Symptoms Screening Tool (PSST). Payesh (Health Monitor). 2011;10(4):421-7. [Persian]

18- Fanaei H, Behboodi Moghadam Z, Kasaeiyan A. Comparison the effects of Ginger and Curcumin in treatment of premenstrual syndrome. ISMJ. 2015;18(3):575-86. [Persian]

19- Rahnama PA, Fallah Huseini H, Mohammadi H, Modares MA, Khajavi Shojaee K, Askari MA, Mozayani P. The effects of zingiber officinal R. on primary dysmenorrhea. Journal of Medicinal Plants. 2010;4(36):81-6. [Persian]

20- Molazem Z, Alhani F, Anooshe M, Vagharseyyedin SA. Epidemiology of dysmenorrhea with dietary habits and exercise. Zahedan J Res Med Sci 2011; 13(3): 47-5. [Persian]

21- Azarnive MS, Tavakoli KS. Level of Physical Activity and Pre Menstrual Syndrome amongst Female University Students. Sci J Hamadan Nurs Midwifery Fac. 2016; 24 (2):68-75. [Persian]

22- Yekke Fallah L, Azimi H, Sadeghi T. The Effect of Aerobic and Walking Exercise on Physical and Psychological Symptoms and Pain of Premenstrual Syndrome. Iran Journal of Nursing. 2013;25(80):46-55. [Persian]

23- Abedi H, Nikseresht A, Tashakoreyan F. Comparison between effects of resistance and endurance exercise training on somatic and affective symptoms of premenstrual syndrome. Journal of Jahrom University of Medical Sciences. 2014;12(3):9-14. [Persian]

24- Omidali F, Valipour DV. The Effect of a Selected Intermittent Training on Symptoms of Pre Menstrual Syndrome. Iran Journal of Nursing. 2016;29 (103):24-32. . [Persian]

25- El-Lithy A, El-Mazny A, Sabbour A, El-Deeb A. Effect of aerobic exercise on premenstrual symptoms, haematological and hormonal parameters in young women. Journal of Obstetrics and Gynaecology. 2015;35(4):389-92.

26- Dehnavi ZM, Jafarnejad F, Goghary SS. The effect of 8 weeks aerobic exercise on severity of physical symptoms of premenstrual syndrome: a clinical trial study. BMC women's health. 2018;18(1):80. 
27- Tsai SY. Effect of yoga exercise on premenstrual symptoms among female employees in Taiwan. Int J Environ Res Public Health. 2016;13(7):721.

28- Siahpour T, Nikbakht M, Rahimi E, Rabiee MA. The Effect of 8 weeks aerobic exercise and yoga on primary dismenorrhea. Armaghane danesh. 2013;18(6):475-83. [Persian]

29- Saneh A, Soraya Akbarabad S. Comparison of mefenamic acid and exercise on reduce primary dysmenorrhea in non-athletes Girls. Razi Journal of Medical Sciences. 2014;21(119):12-7. [Persian]

30- Matthewman G, Lee A, Kaur JG, Daley AJ. Physical activity for primary dysmenorrhea: a systematic review and meta-analysis of randomized controlled trials. Am J Obstet Gynecol. 2018;219(3):255-e1.

31- Esmaili Roozbahani R, Mahdavinajad R. A comparison of the effect of stretching exercises and kinesio taping on the primary dysmenorrhea of high school girls. Journal of Arak University of Medical Sciences. 2015;18(4):1-8. [Persian]

32- Jaafarpour M, Hatefi M, Khani A, Khajavikhan J. Comparative effect of cinnamon and Ibuprofen for treatment of primary dysmenorrhea: a randomized double-blind clinical trial. Journal of clinical and diagnostic research: JCDR. 2015;9(4):QC04.

33- Jahangirifar M, Taebi M, Dolatian M. The effect of Cinnamon on primary dysmenorrhea: a randomized, double-blind clinical trial. Complement Ther Clin Pract. 2018;33:56-60.

34- de Lima RM, dos Reis AC, de Menezes AA, Santos JV, Filho JW, Ferreira JR, de Alencar MV, da Mata AM, Khan IN, Islam A, Uddin SJ. Protective and therapeutic potential of ginger (Zingiber officinale) extract and [6]-gingerol in cancer: A comprehensive review. Phytotherapy research. 2018;32(10):1885-907.

35- Liao BC, Hsieh CW, Liu YC, Tzeng TT, Sun YW, Wung BS. Cinnamaldehyde inhibits the tumor necrosis factor- $\alpha$-induced expression of cell adhesion molecules in endothelial cells by

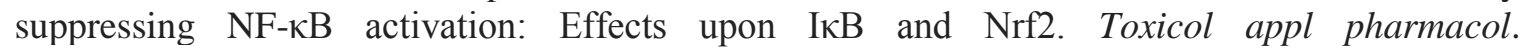
2008;229(2):161-71.

36- Peana AT, De Montis MG, Nieddu E, Spano MT, Paolo SD, Pippia P. Profile of spinal and supraspinal antinociception of (-)-linalool. Eur J Pharmacol. 2004;485(1-3):165-74.

37- Lee HJ, Hyun EA, Yoon WJ, Kim BH, Rhee MH, Kang HK, Cho JY, Yoo ES. In vitro antiinflammatory and anti-oxidative effects of Cinnamomum camphora extracts. J Ethnopharmacol. 2006;103(2):208-16. 